\title{
Cultural Reflections on the Process of Wushu Sports in China
}

\author{
Zhou Jicheng \\ Zhuhai College of Jilin University, Guangdong, Zhuhai, 519041
}

Keywords: Chinese martial arts; sports; traditional culture; national sports; cultural reflection

\begin{abstract}
As the most important carrier in Chinese traditional culture, Chinese Wushu has always been the focal point of disputes between Chinese and Western sports cultures. Whether it is military martial arts or national sports, or even Chinese martial arts actively learn from Western sports, in short, Chinese martial arts has experienced hundreds of years of cultural changes. From the perspective of culturology, this paper describes the process of physical education of Chinese martial arts and some cultural reflections through logical analysis.
\end{abstract}

\section{Introduction}

After entering the 21st century, peace and development have become the theme of the world. In the process of continuous development, China has also established its position as a world economic power. In the process of continuous political and economic development, cultural security has also become a problem that countries must consider. As an important component of Chinese traditional culture, Chinese martial arts has been constrained to a certain extent after undergoing a hundred years of history of sports. On this basis, China has to re-examine the problems brought about by the development of Chinese martial arts sports. . The development of Chinese martial arts sports is essentially an imitation of Western sports. The development of Chinese sports cannot fall into the trap of Western cultural development. It is necessary to eliminate this culture admiring psychology and find the right track to adapt to its own development. In this process, we need to pay special attention to the alienation of Chinese martial arts in the era of China's peaceful rise. This article is based on the integration of Chinese martial arts and Western sports culture, elaborates the cultural misunderstanding of the development of Chinese martial arts sports, and elaborates the future development direction of Chinese martial arts culture from the perspective of sports theory [1].

\section{The Cultural Fusion of Chinese Wushu and Western Sports}

Affected by the concept of Western sports, Chinese martial arts has embarked on the integration of Chinese and Western sports culture in modern times. At the stage of blending Chinese and western sports cultures, people will unnaturally use Western sports theory to interpret the functions and values of Chinese martial arts. That is to say, from the perspective of sports science, the theory of Chinese martial arts is elaborated, and this kind of culture collides and merges. To a certain extent, the distance between Chinese martial arts and Western modern sports science has been shortened, making Chinese martial arts gradually develop towards sports. Secondly, Chinese martial arts gradually demonstrate the characteristics of sports in terms of inheritance methods and teaching methods and contents. The most important manifestation is that the mode of transmission has been transformed from the previous masters and apprentices to the current group practice, which is different from the teacher-inherited teaching and group practice. The scope of dissemination of Chinese martial arts has been expanded, and favorable conditions have been created for the development of martial arts sports in China. Third, the use of sports science theory to explain the Chinese martial arts, to a certain extent, is conducive to the dissemination of Chinese martial arts modernization, and to achieve the direction of the development of Chinese martial arts to sports competition. In short, Chinese martial arts actively absorb Western sports culture in the process of the integration of Western sports culture. It simulates Western martial arts theory to examine Chinese martial arts in the way of Western sports culture and lays a foundation for the development 
of martial arts in China. A solid foundation [2].The martial arts learning pyramid is shown below.

\section{Learning Pyramid}

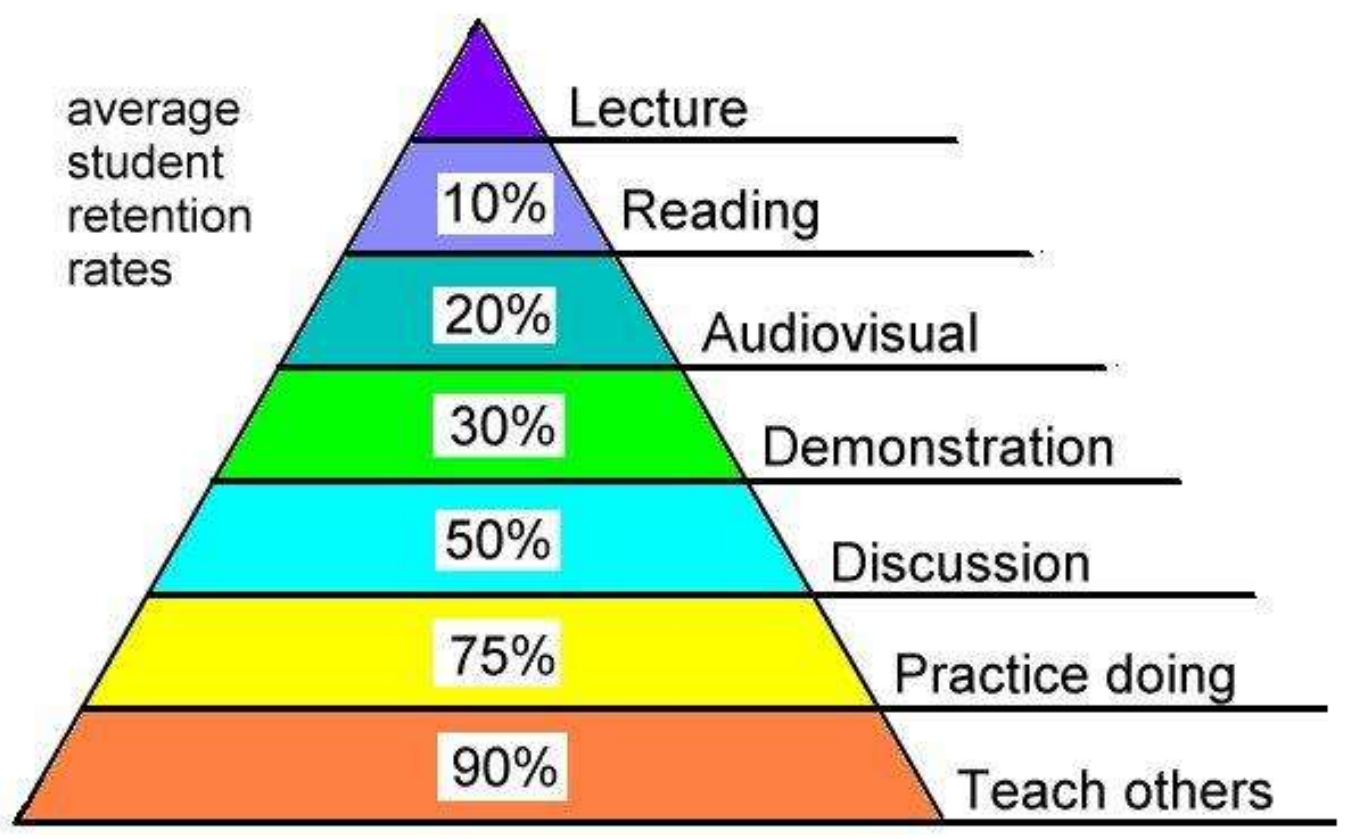

Fig.1 The martial arts learning pyramid

\section{Cultural Misunderstandings of the Development of Wushu Sports in China}

\subsection{Developing Chinese martial arts from the perspective of western sports}

Influenced by different environments and cultural backgrounds, both Chinese and Western sports have formed distinctive thinking modes and national cultures in the process of development. However, many aspects of modern sports in China are basically imitating Western sports. Therefore, its development has obvious westernization. In the process of development and change, Chinese martial arts will inevitably be affected by Western sports culture, especially Since the founding of New China, martial arts has always been regarded as a kind of sporting event in China, which in essence has created a misunderstanding for martial arts. The development and evolution of western sports are related to the game. Later, with the development of the social economy, the game has gradually evolved into modern sports. The purpose of the game is to rest through the rest and then lead to the improvement of work efficiency. This is also the final interpretation of the purpose of the game [3]. However, Chinese martial arts was originally closely linked with war and wrestling. Wrestling has become the ultimate goal of military martial arts. From the perspective of evolutionary history, Chinese martial arts and Western sports are essentially different. From an ideological point of view, the West believes that the game needs fairness and fairness is a relatively serious matter, and sports competitions born on this basis must also be fair and just. However, the Chinese martial arts competition is very different from Western sports. The development of competitive martial arts based on Western sports concepts is also a misunderstanding of Chinese martial arts. From the perspective of form of expression, Western sports pursuit of "higher, faster, and stronger" is aimed at constantly exceeding the limits of man. In other words, western sports pursue speed, reaction and strength. However, Chinese martial arts are different, and Chinese martial arts are more the pursuit of "precision, qi, and deity". Therefore, the use of Western aesthetic perspective to interpret Chinese martial arts is also a misunderstanding of Chinese martial arts. In other words, no matter from the evolutionary process or from the perspectives of concepts and expressions, Chinese martial arts and Western sports are essentially different. Using Western sports perspectives to examine Chinese martial arts is, to a certain extent, a kind of Chinese martial 
arts. Misinterpretation. Chinese martial arts development score as shown in the figure below.

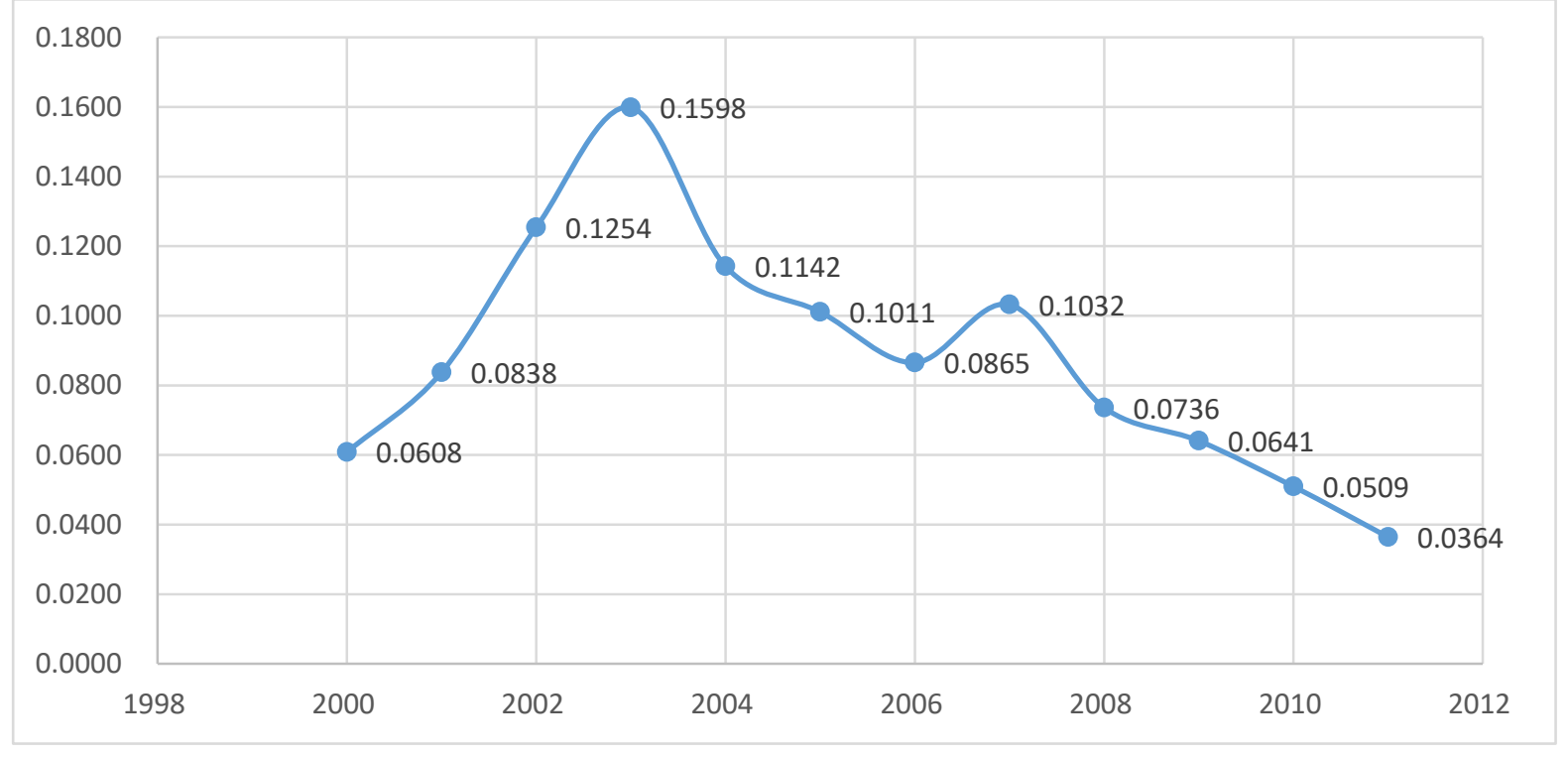

Fig.2 Chinese martial arts development score

\subsection{The development of sports limits the development of Chinese martial arts.}

Although some of the functions of Chinese martial arts belong to the category of sports, many of their connotations are beyond the category of sports. It has been a limitation to the development of Chinese martial arts that the development of Chinese martial arts has always been based on the concept of sports. The development of Chinese martial arts itself has encountered some bottlenecks. If the use of Western sports concepts to frame the development direction of Chinese martial arts will inevitably make the development of Chinese martial arts into a greater dilemma. In short, the development of Chinese martial arts from the perspective of sports philosophy is not only a weakening of the connotation of Chinese martial arts but also a limitation of the development of Chinese martial arts[4].

\section{The Direction of Cultural Development of Chinese Martial Arts from the Perspective of Sports Philosophy}

\subsection{Development and development vision}

The development of Chinese martial arts must carry out careful and careful research on martial arts theory, and then establish an independent scientific system on this basis. Learn to excavate the connotations of Chinese martial arts from various fields. In the course of a hundred years of development, we have made it clear that although Chinese martial arts and Western sports have had cultural integration, the two are fundamentally different. The development of Chinese martial arts must break the shackles of sports concepts, and strengthen the study of the cultural connotation of Chinese martial arts from the perspectives of culturology, arts, history, and sociology. For example, the cultural characteristics of Chinese martial arts are elaborated from the perspective of culturology; the value of Chinese martial arts performance is elaborated from an art level.Vision expansion scoring formula is as follows.

$$
s_{i j}=\frac{1}{n-1} \sum_{k=1}^{n}\left(x_{k i}-\bar{x}_{i}\right)\left(x_{k j}-\bar{x}_{j}\right)
$$

\subsection{Stick to your own eyes}

The development of martial arts must adhere to their own vision and avoid the perception of the value of martial arts by others' eyes. Today's world culture is showing multiple developments. Under this background, Chinese martial arts must find its own cultural value and eliminate the 
prejudice of Western culture through the determination of its independent position. In addition, Chinese martial arts should also eliminate the misunderstanding of the development of sports, and realize the artistic development at the height of national culture.

\subsection{With the world's view}

The world today is an open world. Culture is both a nation and a world. No culture of any nation can develop independently from the world. Naturally, the development of Chinese martial arts is the same. On the basis of adhering to its own characteristics, we must also absorb the essence of world culture and realize the diversified development of martial arts.

\section{Summary}

To sum up, Chinese martial arts has ushered in a relatively good development environment after undergoing a century of sports changes. In an environment of global integration, Chinese martial arts wants to break through the shackles of the concept of sports. It must expand its horizons of development, adhere to its own vision, and also possess the feelings of the world. Only in this way can Chinese martial arts achieve nationalization and individualized development.

\section{Acknowledgement}

Source: Tenth batch of young teachers training program of zhuhai college, Jilin University

\section{References}

[1] Dong Zhu. The Composition of Digital Wushu Instruction Court[J]. Advanced Materials Research,2011,1290(271).

[2] Wei Chen, Chao Liu. Application of Fiber Reinforced Composites for Wushu Equipment[J]. Advanced Materials Research,2013,2108(602).

[3] Wei Chen, Chao Liu. Study on Fiber Reinforced Composite Materials with Wushu Cultural Heritage[J]. Advanced Materials Research,2014,3140(915).

[4] Li Wang, Aijing Li. Research on Morality Education in Wushu Teaching in University and College[M]. Springer Berlin Heidelberg:2012-06-15. 